\title{
Prospects of waste-heat recovery from a real industry using thermoelectric generators: Economic and power output analysis.
}

\author{
Miguel Araiz ${ }^{\mathrm{a}, \mathrm{b}, *}$, Álvaro Casi ${ }^{\mathrm{a}}$, Leyre Catalán ${ }^{\mathrm{a}, \mathrm{b}}$, Álvaro Martínez ${ }^{\mathrm{a}, \mathrm{b}}$, David Astrain ${ }^{\mathrm{a}, \mathrm{b}}$ \\ ${ }^{a}$ Department of Engineering, Public University of Navarre, Campus Arrosadía, Pamplona (Navarre), Spain \\ ${ }^{b}$ Institute of Smart Cities, Public University of Navarre, Campus Arrosadía, Pamplona (Navarre), Spain
}

\begin{abstract}
One of the options to reduce industrial energy costs and the environmental impact is to recover the waste-heat produce in some processes. This paper proposes the use of thermoelectric generators at a stone wool manufacturing plant to transform waste-heat from a hot gas flow into useful electricity. A combination of two computational models, previously developed and validated, has been used to perform the optimization from a double point of view: power output and economic cost. The proposed thermoelectric generator includes fin dissipaters and biphasic thermosyphons as the hot and cold side heat exchangers respectively. The model takes into account the temperature drop along the duct where the gases flow, the electric consumption of the auxiliary equipment, and the configuration and geometry of the heat exchangers. After the simulations a maximum net power production of $45838 \mathrm{~W}$ is achieved considering an occupancy ratio of 0.40 and a fin spacing of $10 \mathrm{~mm}$. The installation cost is minimized to $10.6 € / \mathrm{W}$ with an occupancy ratio of 0.24. Besides, the Levelised Cost of Electricity, $L C O E$, is estimated for a thermoelectric generator for the first time. It is necessary to use standar methodologies to compare this technology to others. The LCOE estimated for the proposed design is around $15 \mathrm{c} € / \mathrm{kWh}$ within the ranges of current energy sources, proving, in this way, the capabilities of waste-heat recovery from industrial processes at reasonable prices with thermoelectric generators.
\end{abstract}

Keywords: thermoelectric generator, waste-heat recovery, computational model, power generation, economic analysis, $\mathrm{LCOE}$

\section{Introduction}

In many manufacturing plants, there exist high tem- ${ }_{25}$ perature processes that release thermal energy to the environment without being used, the so-called waste-heat 5 energy. It is estimated that 20075 TWh of energy were released to the atmosphere in 2018 in the US [1]. In order to reduce industrial energy costs and their associated environmental impacts, it is essential to identify the availability of waste-heat energy and try to recover it [2]. There

10 are many technologies able to use this energy, such us, recuperative burners, economisers, waste-heat boilers or regenerators [3]. Most of them use this energy in the same way it is released, as thermal energy. However, there are other alternatives that transform this heat into electricity.

15 It is the case of Organic Rankine or Kalina cycles, thermodynamic cycles that convert waste-heat into electrical energy and improve the energy efficiency of a process. Due to the complexity of these cycles, some researchers propose thermoelectricity as an alternative to the former systems.

20 Thermoelectric generators (TEG) can directly convert any thermal energy into electricity in a simple and scalable way [4].

\footnotetext{
${ }^{*}$ Corresponding author

Email address: miguel.araiz@unavarra.es (Miguel Araiz)
}

A thermoelectric generator is a device that directly transforms a heat flux into electricity by simply placing thermoelectric modules between a heat source and a heat sink, usually the environment. The conversion efficiency of these devices is low compared to other energy sources, and the requirements for the installation are sometimes difficult to achieve. Besides, the use of heat exchangers is required in order to bring the modules face temperatures closer to the source and sink, and therefore, increase their electric power generation. There is a wide range of technologies that can be used for such purpose, finned dissipaters, heat-pipes, water cooling systems or thermosyphons [5].

Despite the drawbacks mentioned above, several prototypes of thermoelectric generators applied to waste-heat recovery in industrial environments can be found on the literature. All of them are small-scale devices able to produce less than $100 \mathrm{~W}$ of electric power. For instance, Nesarajah analyses the performance of a thermoelectric generator of just $2 \mathrm{~W}$ to recover waste heat from exhaust gas flow [6]. Remeli proposes a thermoelectric generator with bismuth-telluride modules sandwiched between heat-pipes ${ }_{45}$ that is able to produce around $7 \mathrm{~W}$ of electric power [7] and Chiarotti, using and active water cooling system, is able to generate up to $36 \mathrm{~W}$ [8]. Aranguren develops a thermoelectric generator placed at the exhaust of a combustion 


\section{Nomenclature}

\section{Variables}

$\Delta P \quad$ pressure losses $(\mathrm{Pa})$

$\delta \quad$ occupancy ratio

$\dot{m} \quad$ mass flow $(\mathrm{kg} / \mathrm{s})$

$\dot{Q} \quad$ heat flux (W)

$\dot{V} \quad$ volumetric flow $\left(\mathrm{m}^{3} / \mathrm{h}\right)$

$\dot{W} \quad$ electric power $(\mathrm{W})$

$\eta \quad$ efficiency

$A \quad$ area or surface $\left(\mathrm{m}^{2}\right)$

C $\quad$ cost $(€)$

cp specific heat $\left(\mathrm{J} /\left(\mathrm{kg}^{\circ} \mathrm{C}\right)\right)$

$D \quad$ dismantling cost $(€)$

$E \quad$ electric energy $(\mathrm{kWh})$

$F \quad$ fuel cost $(€)$

$I \quad$ installation cost $(€)$

$k \quad$ discount rate $(\%)$

$L \quad$ length (m)

$L C O E$ levelised cost of electricity $(€ / \mathrm{kWh})$

$M \quad$ maintenance cost $(€)$

$N \quad$ number of thermoelectric modules

$R$ thermal resistance $\left({ }^{\circ} \mathrm{C} / \mathrm{W}\right)$

$S \quad$ fin spacing $(\mathrm{mm})$

$T$ temperature $\left({ }^{\circ} \mathrm{C}\right)$ cond conduction heat transfer

const constriction

$c v \quad$ convection heat transfer

$d$ duct

ext external

extra other elements considered

fan related to the fan

fin fins of the hot side dissipater

$g$ hot gas flow

gen generated power

$H$ hot source

$h \quad$ hot side

$H_{H E}$ hot side heat exchanger

$i \quad$ ith section of the duct

in inlet

net net, removing auxiliary consumption

out outlet

sat saturation temperature

$t$ related tube

total total

year yearly produced

\section{Subscripts}

$a m b$ ambient temperature

aux auxiliary consumption

c cold side

$C_{H E} \quad$ cold side heat exchanger

\section{Abbreviations}

LCOE levelised cost of electricity

MPPT Maximum Power Point Tracker

TEG thermoelectric generator

TEM thermoelectric module

TSP biphasic thermosyphon chamber and, considering the consumption of the auxiliary 60 equipment used, it generates $21.56 \mathrm{~W}$ [9]. Another prototype developed is the one proposed by Montecucco focused on the recovery of heat from stoves. The designed system contains a MPPT and is able to produce up to $27 \mathrm{~W}$ of electric power during the experiments [10].

The complexity of installing prototypes in a real process, dealing with system dimension, contact resistances, assembly pressure, mismatched interfaces, efficient cooling systems, justifies this few examples of experimental generators. That is why most of the studies of energy harvesting 70 in industries use computational models to simulate and estimate the potential of waste-heat recovery.

Some of these studies are not applied to a real process, such as the theoretical analysis of Khalil that investigates different configurations of a thermoelectric generator for 65 waste heat recovery from a made-up chimney [11]. Other researchers proposed a combination of thermoelectricity with other technologies for waste heat recovery in industry. For instance, Khanmohammadi integrates a thermoelectric generator with the production of liquefied natural gas [12] and Habibollahzade proposed the combination of 
parabolic solar collectors, electrolysis and thermoelectric generators [13].

Among the studies that use just thermoelectric generators for waste-heat recovery the analysis of the perfor75 mance of those systems is partial, either because they do not consider any alteration on the hot source, because they do not take into account the consumption of the auxiliary equipment or because they do not perform any economic analysis. For example, Meng proposes a thermoelectric s system able to produce up to $1.47 \mathrm{~kW}$ of electric power from a hot gas flow at $350^{\circ} \mathrm{C}$ [14]. However, he does not consider the temperature drop of the current and does not any economic analysis. Elankovan presents an evaluation of the performance of a thermoelectric generator applied to a long duct in which the temperature drop of the hot source is considered. By analysing different thermal sys-130 tem configurations the maximum output power achieved is $172.34 \mathrm{~kW}$. However, there is no evaluation of the effect of the auxiliary systems or any economic study [15].

90 Similarly, Barma applies thermoelectric generators to a biomass fired thermal oil heater and simulates its perfor-135 mance considering different thermoelectric modules. But again, there is no analysis of the economic impact on the proposal [16].

As Ando remarks, the development of more economic studies related to thermoelectric generators would boost 140 the implementation of such systems in the industry [17]. In all these analysis, it is essential to consider the temperature drop of the gases as well as the electric consumption of the auxiliary in order to get accurate results [18]. From the works that do perform an economic analysis, most of ${ }^{145}$ them just consider the cost of the thermoelectric material $[19,20]$ or analyse the cost by estimating the fuel saving ratio $[21,22]$. In addition to that, Benday takes into account the cost of the heat exchangers which results to have a strong influence over the total cost highlighting the im-150 portance of an efficient heat transfer design [23]. Mirhosseini performs a power optimization of a thermoelectric waste recovery system around a rotary cement kiln and does an estimation of the cost of such design, considering the bulk thermoelectric material, the manufacturing cost, ${ }^{155}$ the heat exchangers and the installation cost. However, they do not include the economic study in the optimization of the generator [24].

This lack of agreement when evaluating the economic aspect of thermoelectric generators has motivated the use ${ }^{160}$ of a standard methodology to determine the cost that the electricity produced by thermoelectric genertos should have. In this way, not only a comparisson betwen differnt thermoelectric generatos can be done, but also among other energy sources available now. The methodology cho-165 sen has been the Levelised Cost of Electricity, that is commonly used to economically evaluate both energy sources [25] and other waste-heat recovery technologies [26]. This ${ }_{125}$ is the first time that the $L C O E$ is used to economically analysed the implementation of thermoelectric generators.

The work presented here proposes a computational study

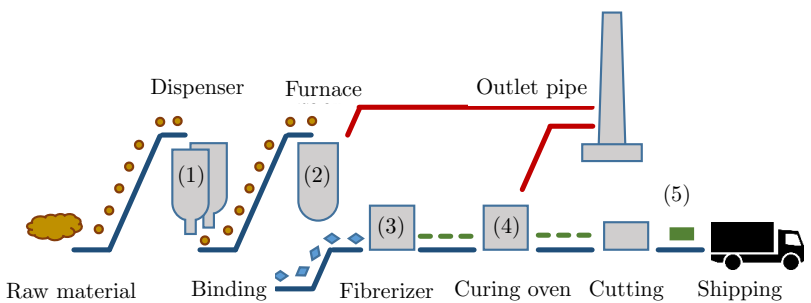

Figure 1: Stone wool insulation manufacturing flow chart.

and an optimized design of a thermoelectric generator for waste-heat recovery in a real manufacturing plant in Navarre (Spain). The analysis includes both a power and an economical optimization for the installation of such generator. As the optimization of the heat exchangers, that are included in a thermoelectric generator is essential, the methodology followed uses a combination of two computational models previously developed and validated [18, 27]. The first model simulates the behaviour of a thermoelectric generator installed at a exhaust chimney. This computational tool considers the temperature drop of the hot gases that flow through the pipe and takes into account the design of the heat exchangers employed at both sides of the thermoelectric modules. The second one simulates the performance of a biphasic thermosyphon and can be used as a design tool for such heat exchangers combined with thermoelectric generators. Due to the importance of the auxiliary consumption in such devices, the idea of using passive systems would benefit the whole generator and it would be the first time that these passive biphasic heat exchangers are used in a thermoelectric generator for a real industrial application.

The study has been made from two points of view: the first one trying to maximize the electric power output and the second one trying to minimize the installation cost of the whole thermoelectric generator. Besides, an estimation of the Levelised Cost of Electricity, $L C O E$, has been done in order to include this technology in the electric energy production framework. Section 2 describes the industrial process and presents the hot source selected for this study. After that, Section 3 presents the proposed design for the thermoelectric generator, the computational model used as well as the input parameters considered in the simulations. It also contains the economic estimation methodology followed. Finally, Section 4 shows the results derived from the simulations and the analysis of the solution achieved and Section 5 gathers the conclusions of the work.

\section{Industrial process}

The industry selected for this study manufactures stone wool insulation products mainly for the construction sector, such as, ceiling, exterior walls, floors and pipes insu- 
Table 1: Conditions of the most relevant exhaust pipes and hot gases analysed.

\begin{tabular}{llcccc}
\hline & Location & $\begin{array}{c}\text { Length } \\
\mathrm{m}\end{array}$ & $\begin{array}{c}\text { Diameter } \\
\mathrm{m}\end{array}$ & $\begin{array}{c}\text { Flow } \\
\mathrm{m}^{3} / \mathrm{s}\end{array}$ & $\begin{array}{c}\text { Temperature } \\
{ }^{\circ} \mathrm{C}\end{array}$ \\
\hline A & Furnace & 30 & 0.8 & 25000 & 300 \\
B & Curing oven & 30 & 0.9 & 40000 & 230 \\
C & Cooling area & 12 & 0.9 & 45000 & 100 \\
\hline
\end{tabular}

lation. The flow chart of its manufacturing process can be seen in Figure 1. Volcanic stone is used as raw material and enters the furnace through a dispenser (1). This rock is heated in the furnace (2) to the molten state temperature of $1300{ }^{\circ} \mathrm{C}$ to $1600^{\circ} \mathrm{C}$. The molten mineral is carried to a fibrerizer (3) where a high-speed-rotor revolves the mass to form fibres. At this point, a chemical binding agent is added to them and, after several minutes in a curing oven (4), the insulation has its defined structure as rock wool. Finally, it is cut to its final shape and packed (5) ready for shipping.

In a process that works with high temperatures, as the one presented, there are several potential hot spots than can be used as heat sources for a thermoelectric generator. Most of them consist of a current of hot gases that flow through different pipes. The ones analysed for this study are gathered in Table 1 . In order to maximize the power $_{220}$ output from a thermoelectric generator it is necessary to get as high temperature as possible on the hot side of the thermoelectric modules and this mainly depends on two factors: temperature of the gases current and its flow [9]. On one hand, the higher the temperature of the gases current, the higher the temperature at the hot face, which increases the temperature difference between both sides ${ }_{225}$ and, thus, enhances the power generation. On the other hand, the hot gases that flow through a duct suffer a temperature drop as they are releasing part of their energy to the thermoelectric modules. This causes a reduction on the electric production of the modules located at the end ${ }_{230}$ of the pipe. Therefore, it is desirable to use gases currents with high flow, so that this effect is minimized.

Due to these reasons, location $\mathrm{C}$ has been rejected from the study, its temperature is too low to make the production of electricity profitable, despite the high volumetric ${ }_{235}$ flow of this current. Locations A and B, the exhaust of the furnace and the curing oven respectively, offer the highest temperatures, but location B is more suitable to be used as the heat source due to the great volumetric flow difference between them. The gases flow at $40000 \mathrm{~m}^{3} / \mathrm{h}$ so the ${ }_{240}$ temperature drop will be minimal, maintaining the electric power output at acceptable rates.

Location B consists of a vertical 30-meter-long pipe through which $230{ }^{\circ} \mathrm{C}$ gases are released from the curing oven to the atmosphere. This round duct has a diameter of ${ }_{245}$ $0.9 \mathrm{~m}$, however, since the thermoelectric modules require

215 a flat surface to be installed, a square duct of $0.8 \mathrm{~m}$ side is proposed for the final design. This configuration would provide the same cross section to the gases flow. The ex-

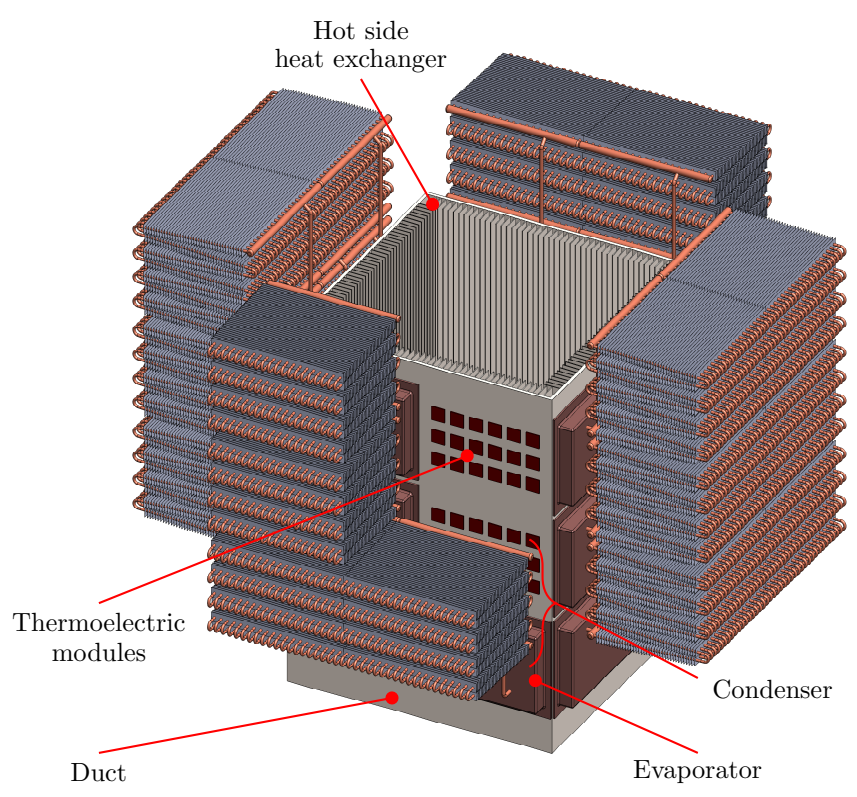

Figure 2: Proposed design of the thermoelectric generator in this study.

haust duct is placed outside the industrial plant, where the surrounding air flows on average at $13{ }^{\circ} \mathrm{C}$ and a speed of $3.8 \mathrm{~m} / \mathrm{s}$.

\section{Simulation methodology}

The proposed design for the thermoelectric generator can be seen in Figure 2. The hot gases flow through a square duct and the thermoelectric modules are placed on the external face of its walls. Commercial thermoelectric modules have been used in the simulations, specifically TG12-8-01 from Marlow Industries [28], as they have an operation temperature limit of $230^{\circ} \mathrm{C}$ and the inlet temperature of the gases is precisely $230^{\circ} \mathrm{C}$, so this limit would never be exceeded.

As it has been explained in the introduction, it is essential to include heat exchangers at both sides of the modules to increase the temperature difference between the faces. Finned dissipaters have been chosen for the hot side, since they are cheap, simple and easy to install on the interior of the duct. Thus, the heat absorption from the hot gas flow would be enhanced without affecting the current to a great extent. The pressure losses caused by the insertion of the fins inside the duct have also been considered and would be added to the simulations as and extra electric consumption. With the installation of a thermoelectric generator as the one here proposed, a bigger fan would be necessary to overcome the pressure losses caused by the internal fins. This auxiliary consumption will be estimated according to Equation 1 where $\Delta P_{\text {fan }}$ are the pressure losses of the gas flow; $\dot{V}_{g}$ the volumetric flow of the gases; and $\eta_{f a n}$ the efficiency of the considered fan. 


$$
\dot{W}_{\text {aux }}=\frac{\Delta P_{\text {fan }} \dot{V}_{g}}{\eta_{\text {fan }}}
$$

For the cold side, biphasic thermosyphons heat exchangers have been selected. These devices can work under free convection so no auxiliary equipment is needed to $0^{30}$ release the heat to the ambient and the movement of the fluid occurs thanks to density differences. This system get proper thermal resistance values that fit the necessities in a thermoelectric generator.

Figure 2 represents the thermoelectric generators $\mathrm{cov}^{-305}$ ering $1 \mathrm{~m}$ of the exhaust duct. The proposal is to place several of these generators along the pipe, starting from the bottom. Furthermore, this manufacturing plant has a temperature limit of $120^{\circ} \mathrm{C}$ for releasing the gases to the osphere at the outlet of the duct. Therefore, it will be necessary to have this restriction in mind and limit the number of thermoelectric generators installed where the gases temperature get to that value. After the simulation of each section the outlet temperature is checked and compared to that limit. If this parameter is bigger than ${ }^{315}$ $120^{\circ} \mathrm{C}$, more thermoelectric generators can be used, if not, the generators would just cover the duct up to that point.

\subsection{Simulation variables}

There are many parameters that can be considered in ${ }^{32}$ the simulations. However, some of them have been set constant to reduce the total number of runs to perform. The fixed variables have low influence on the power output or the installation cost, or are defined by constructive aspects. An analysis of the main parts involved in the thermoelectric generator and the values of the main parameters is presented below.

\section{Thermoelectric modules}

The number of thermoelectric modules is one of the input variables considered in the simulations since they have a strong influence over the performance of the heat exchangers, the installation cost and the length occupied by the generator. A great number of modules would absorb a huge amount of heat from the gases dropping their temperature to $120^{\circ} \mathrm{C}$ before reaching the end of the duct. On the contrary, a low number of thermoelectric modules would allow to occupy the whole duct. This parameter is introduced in the computational model trough the occupancy ratio, $\delta$, defined by Equation 2. This factor represents the surface taken up by each of every $N$ module,

$$
\delta=\frac{N A_{T E M}}{A_{d}}
$$

\section{Hot side heat exchanger}

The hot side heat exchanger consists of fins located on the inner wall of the duct. They are $50 \mathrm{~mm}$ high and $1.5 \mathrm{~mm}$ width. ANSYS Fluent software has been used to

295 study the influence of fin spacing over the thermal resistance of the heat exchanger, as well as to estimate the pressure losses of the gas flow for the different configurations. As the thermal resistance depends not only on the gap between fins but also on the number of thermoelectric modules installed, the occupancy ratio, $\delta$, has also been considered.

Figure 3 shows the functions obtained from the ANSYS simulations that will be introduced to the computational model for the whole study. They represent the thermal resistance of the heat exchangers per thermoelectric module as a function of the speed of the gases inside and the occupancy ratio for different fin spacings. On the one hand, as it can be seen, all the analysed geometries follow the same trend, an increase of the thermal resistance with the occupancy ratio which is caused by a drop of the available exchange area for each module. On the other hand, reducing the fin spacing increases the exchange surface enhancing the heat transfer and, therefore, speeds the gases up outperforming the convection coefficients, reducing the thermal resistances per module.

The pressure losses caused by the considered heat exchangers are independent of the occupancy ratio, and are shown in Figure 4. A considerable increase in the pressure losses is seen when the fin spacing is reduced from $14 \mathrm{~mm}$ to $6 \mathrm{~mm}$. This fact will have a noticeable impact on the auxiliary consumption of the fan that propels the gases through the duct.

\section{Cold side heat exchanger}

The cold side heat exchanger will be located on the outside part of the duct, covering the thermoelectric modules place on it. Hence the size of the evaporator is limited by the side of that duct, as it can be seen in Figure 2. The evaporator is fixed to $400 \mathrm{~mm} \times 300 \mathrm{~mm}$, made of copper, and with 3 mm-wide-walls.

In order to use as much external duct as possible, the evaporators of two consecutive thermoelectric generators should be placed one after the other. This will limit the height that each condenser may have, so as not to collide with the rest of the components of the thermosyphons, as it is shown in Figure 5. The height of the condensers will be $300 \mathrm{~mm}$ and they will be composed of copper tubes with a diameter of $7 \mathrm{~mm}$ and a thickness of $1 \mathrm{~mm}$. Aluminium fins will be included to increase the convection area. They will be $30 \mathrm{~mm}$ high and will have a spacing of $5 \mathrm{~mm}$. To design a compact condenser the tubes will have a tilt angle of $5^{\circ}$, enough to make the liquid condensed drain back to the evaporator [29], and a total length of $3.4 \mathrm{~m}$ each, divided in 8 levels. The input parameter for the simulations will be the number of parallel tubes that each condenser may 45 have. In this way, the influence of the convective area over the performance of the thermoelectric generator can be studied. Water will be used as the working fluid inside the heat exchanger. 


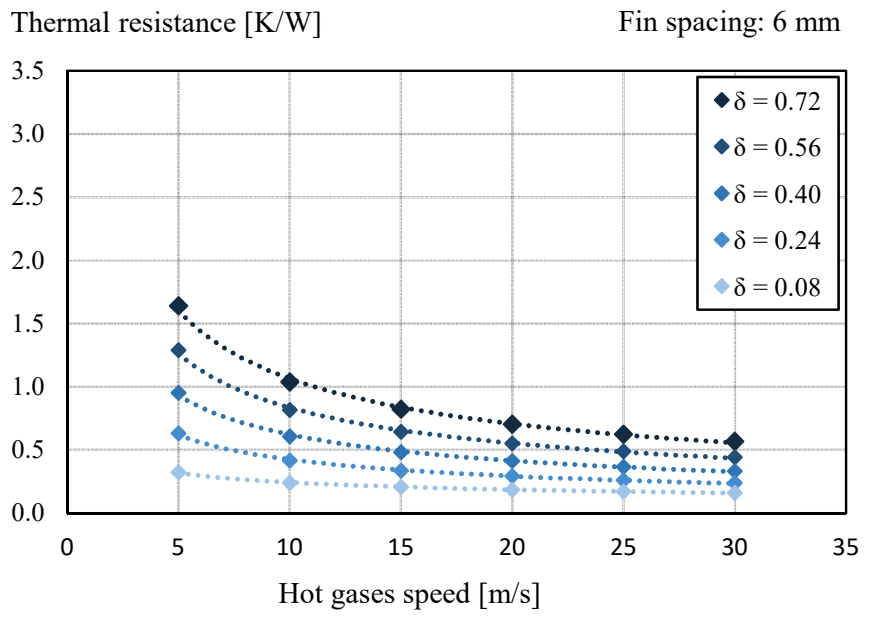

Thermal resistance $[\mathrm{K} / \mathrm{W}]$

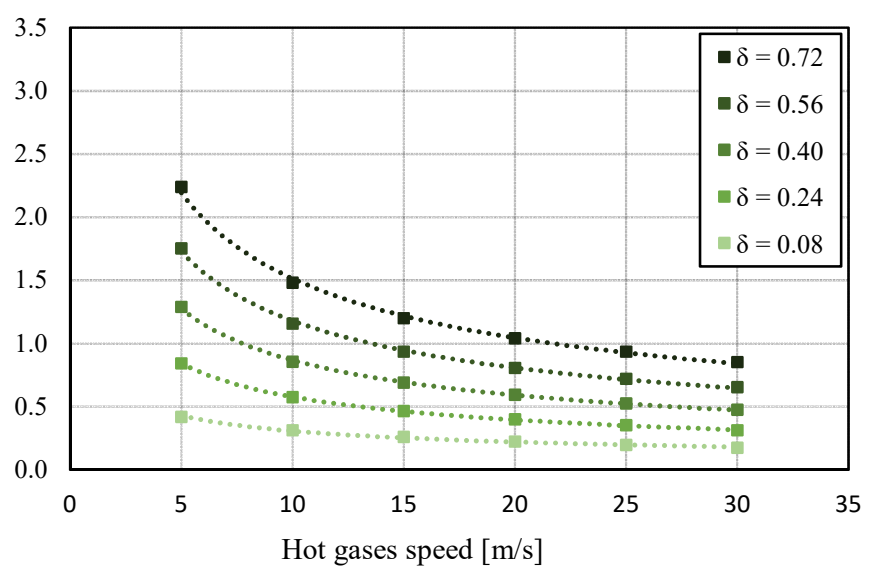

Thermal resistance $[\mathrm{K} / \mathrm{W}]$

Fin spacing: $14 \mathrm{~mm}$

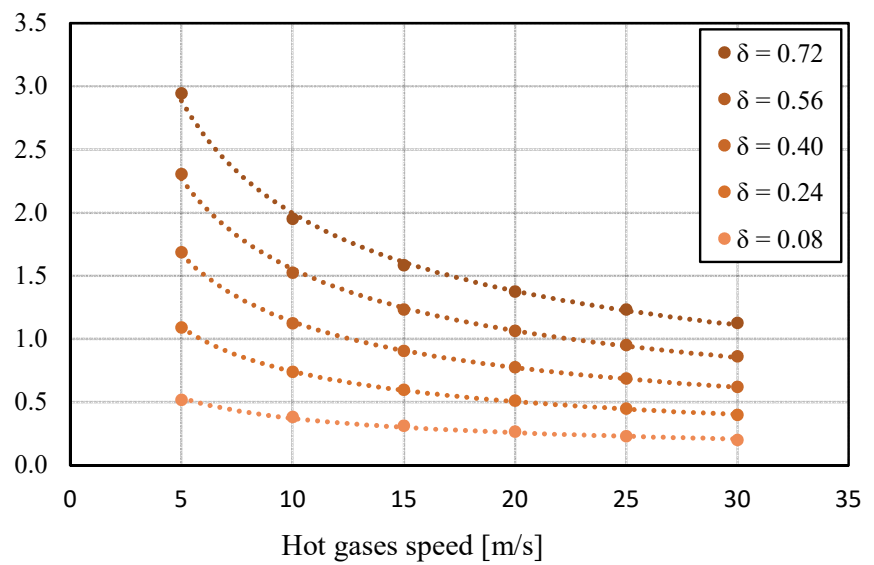

Figure 3: Thermal resistances per thermoelectric module of the hot side heat exchangers with different fin spacings and occupancy ratios.

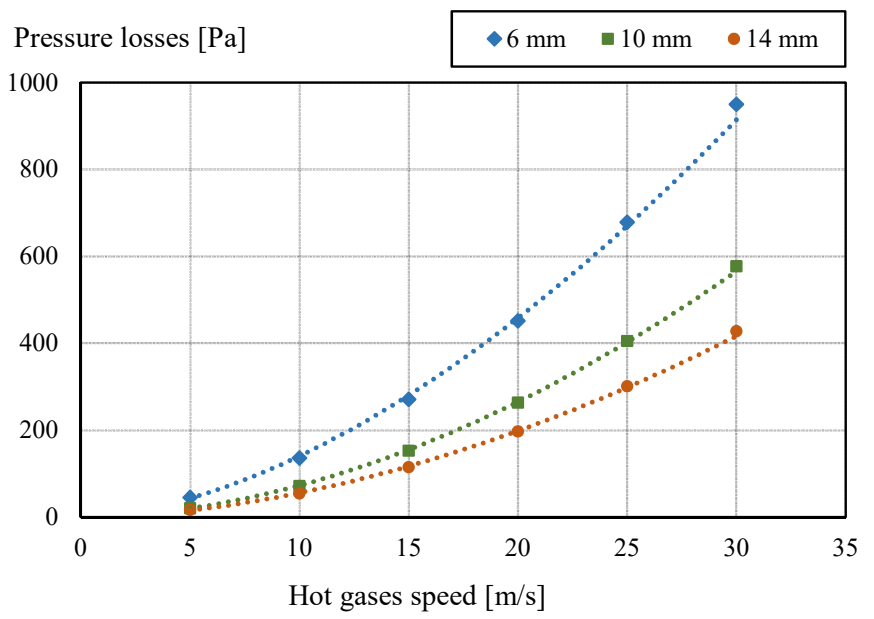

Figure 4: Pressure losses produced in $1 \mathrm{~m}$ of duct with fins on the inner walls.

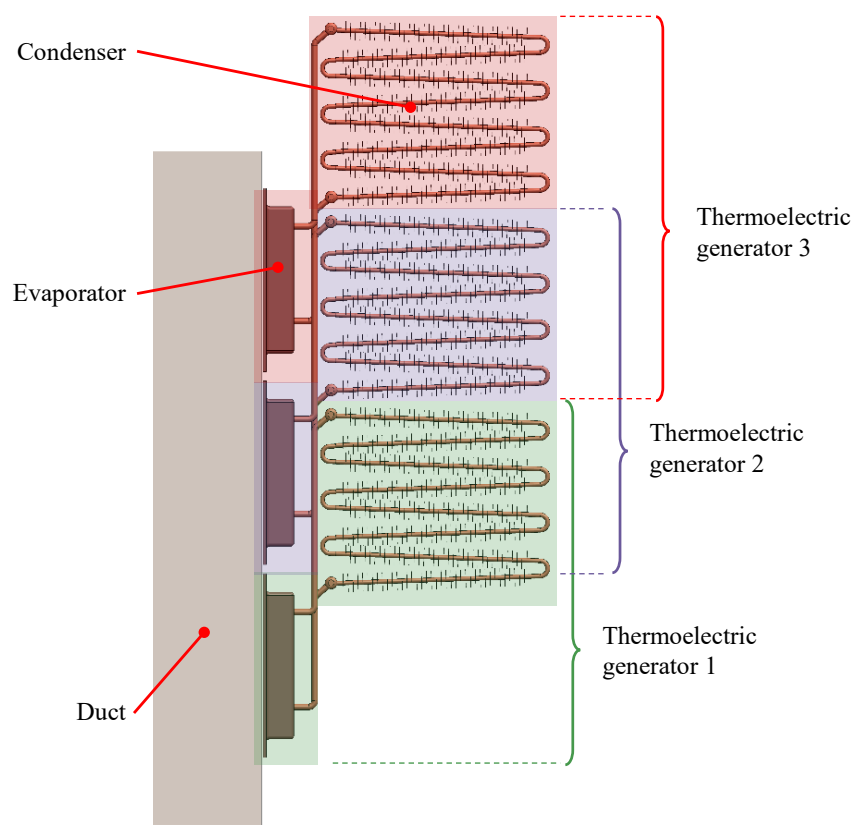

Figure 5: Distribution of the thermosyphons and their condensers along the duct. 


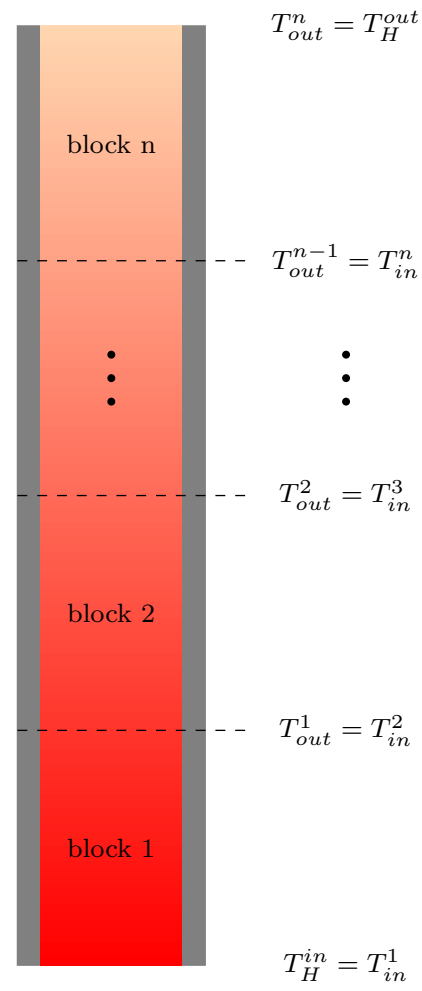

Figure 6: Division of the pipe into $n$ blocks.

\subsection{Computational methodology}

The followed methodology combines two models previ-400 ously validated to perform a bunch of simulations to evaluate the performance of thermoelectric generators with different configurations and compare the economic cost between them. The first computational model employed is able to predict the total electric power output from a thermoelectric generator used for waste-heat recovery from $\mathrm{a}_{40}$ hot gas current that flows through a duct [18]. This tool considers the temperature drop that suffers the gas flow as it exchanges heat with the thermoelectric generator. This is taken into account by dividing the pipe into several blocks, as shown in Figure 6. Each one of the blocks is solved assuming an uniform temperature of the hot gases, $T_{H}^{i}$; which is estimated, according to Equation 3, with the mean temperature of the inlet and outlet temperatures of the piece of the duct considered, $T_{i n}^{i}$ and $T_{\text {out }}^{i}$ respectively. For that purpose, the outlet temperature is calculated, in ${ }_{415}$ an iterative process, using the heat absorbed from the exhaust gases, $\dot{Q}^{i}$; their mass flow, $\dot{m}_{\text {gas }}$; their specific heat, $c_{p}$; and the inlet temperature, $T_{i n}^{i}$; as Equation 4 describes.

$$
\begin{gathered}
T_{H}^{i}=\frac{T_{\text {in }}^{i}+T_{\text {out }}^{i}}{2} \\
T_{\text {out }}^{i}=T_{\text {in }}^{i}-\frac{\dot{Q}^{i}}{\dot{m}_{\text {gas }} c_{p}}
\end{gathered}
$$

This model is based on the finite differences method to figure out the power output by solving the thermoelectric phenomena. It also takes into account the heat exchangers used at both side of the thermoelectric modules [18]. For the simulations here presented, the hot side heat exchanger introduced to the model by its thermal resistance, $R_{H E_{-} h}$, value obtained from ANSYS Fluent simulations. For the case of the cold side dissipater, biphasic thermosyphons have been chosen as the heat exchangers to release the excess heat to the atmosphere, due to their lack moving parts or auxiliary equipment. In order to use these devices in the thermoelectric generator proposed, a second computational model is integrated into the first one adding the thermal resistances from the node $T_{c}$, that represents the cold face of the thermoelectric modules to the note $T_{a m b}$, representing the ambient temeprature. This model considers the heat transfer phenomena along the biphasic device: conduction and constriction thermal resistances, $R_{\text {cond }_{e}}, R_{\text {cond }_{t}}, R_{\text {const }}$; boiling and condensation heat transfer, $R_{b}, R_{c v}$; and convection to the environment, $R_{h}$; and is able to estimate the performance of such devices according to their geometry, size, and configuration $[27]$.

Both models have been combined leading to the electric resistances scheme showed in Figure 7. This model now includes all the components implicated in the generators: hot source and its temperature variations along the pipe; hot side heat exchanger; thermal contact resistances; modules and the thermoelectric phenomena involved; thermal losses through the insulation and the assembly elements; and cold side heat exchangers. It enables the study of the variation of the generator's performance with the geometry and configuration of the heat exchangers or the modules.

\section{Duct discretization}

As explained before, this computational model considers the temperature drop of the gas flow due to the installation of some thermoelectric generators. In order to properly cover this issue it is necessary to split the duct into several blocks so that the simulated hot source temperature is closer to the real one. However, this division raises the computational cost of the simulations. A sensitivity study has been performed to compare the output variables and the computing time as a factor of the number of segments considered. Figure 8 shows the variation of the power output of the thermoelectric generators and the computational cost of every simulation. The output parameter remains virtually constant from 10 divisions, in contrast with the computing time that suffers a linear growth. Therefore, in this case, it is enough to split the duct into 10 blocks when performing the simulations.

As a sumary, Table 2 collects the levels of the factors considered in the analysis presented in this work, resulting in a total of 45 simulations. 


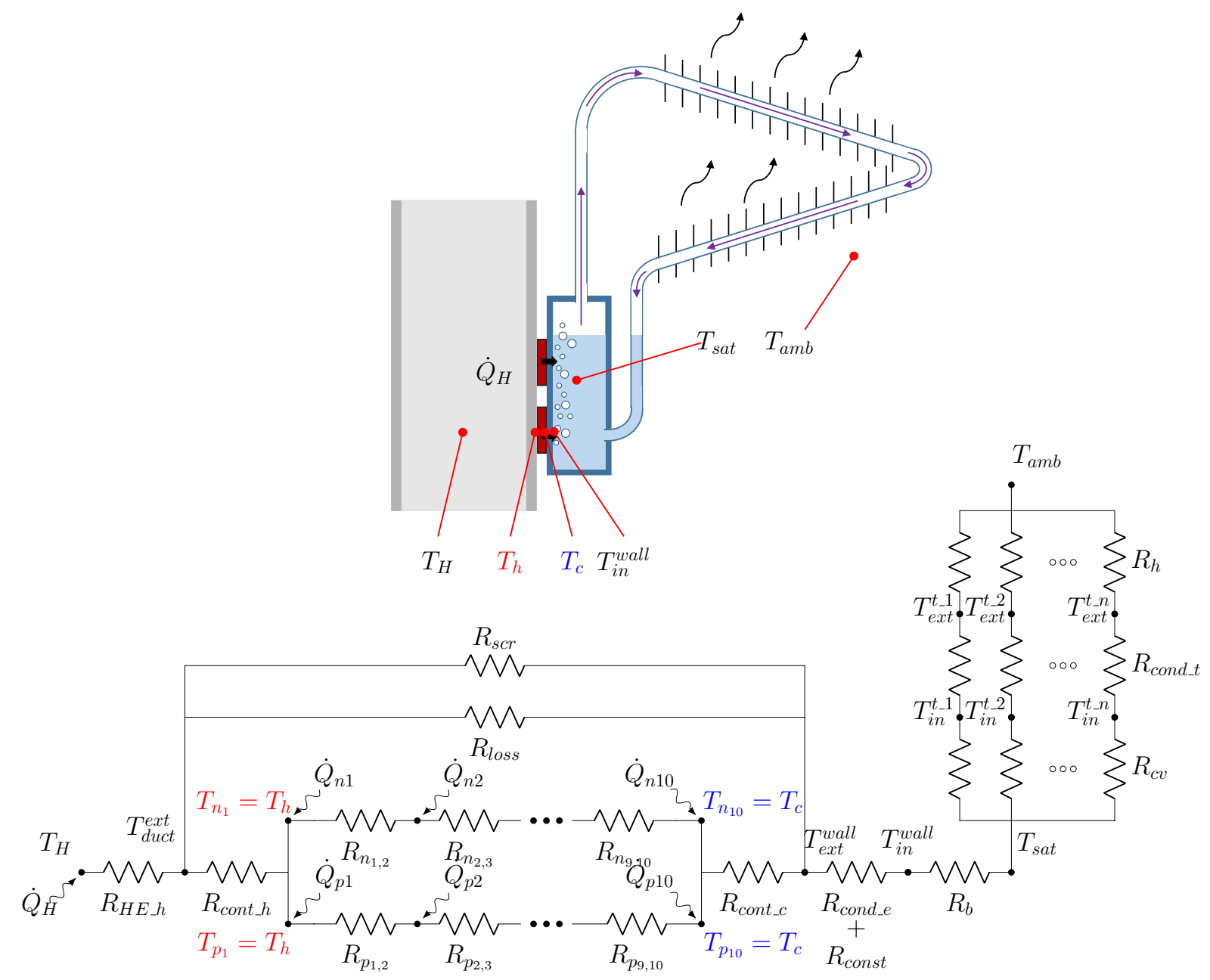

Figure 7: Thermal-electric analogy of the two computational models combined [18, 27]: thermoelectric generation + biphasic thermosyphons.

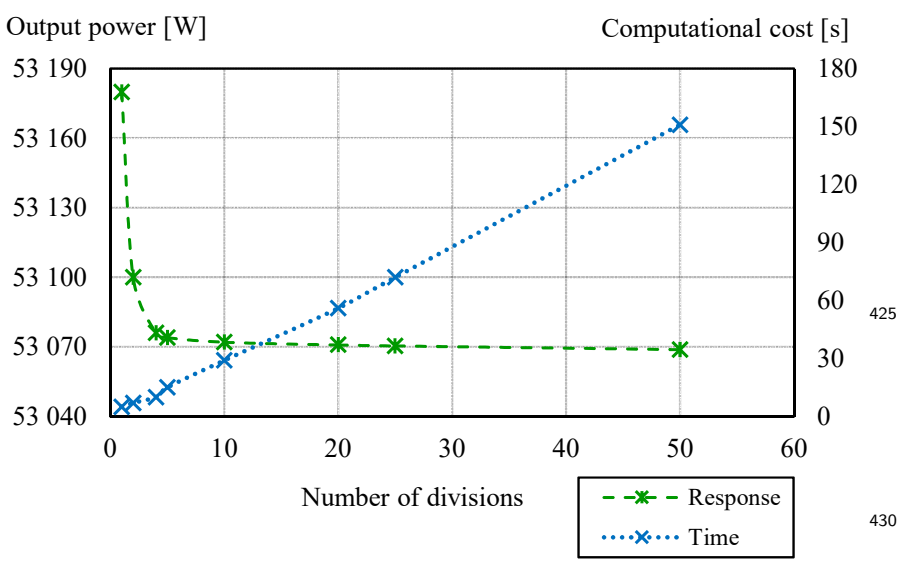

Figure 8: Sensitivity analysis for selecting the number of divisions of the pipe.
Table 2: Input variables considered in the simulations.

\begin{tabular}{lr}
\hline Factor & Levels \\
\hline Occupancy ratio, $\delta$ & $0.08 ; 0.24 ; 0.40 ; 0.56$ and 0.72 \\
Fin spacing, $S$ & $6 ; 10$ and $14 \mathrm{~mm}$ \\
Tubes in the condenser & $20 ; 30$ and 40 \\
\hline
\end{tabular}

\section{Output parameters}

The ouput variables obtained as results of the simulations include: the outlet temperature of the gas flow, and hence the length of the duct occupied by the generator, the total electric power produced by the thermoelectric generators, and the electric consumption of the fan that pumps the gases. Therefore, the net electric output can be calculated.

\subsection{Cost estimation}

Once each simulation is done, the economic cost of the installation of the thermoelectric generators can be estimated. The price is calculated according to Equation 5 and it includes the cost of the $N$ thermoelectric modules 
employed, $C_{T E M}$; the cost of the heat exchangers located at both sides of the modules, $C_{H_{-} H E}$ and $C_{C_{-} H E}$; the extra445 charge of including a more powerful fan to overcome the pressure losses due to the addition of fins inside the duct, $C_{f a n}$; and other costs that include the price of the insulation material used, the assembly elements or the interface materials, $C_{\text {extra }}$.

$$
C_{\text {total }}=N \cdot C_{T E M}+C_{H_{-} H E}+C_{C_{-} H E}+C_{f a n}+C_{e x t r a}
$$

The unit price of the thermoelectric modules, $C_{T E M}$, according to the figures obtained from some manufacturers $[28,30,31]$, has been set to $20 €$.

With regard to the hot side heat exchanger, knowing the length of the duct occupied by the generators, $L_{c}$, and the fin spacing considered in each simulation that sets the number of fins placed, $n_{f i n}$, the amount of material employed can be estimated. Considering a price for steel sheets of $0.9 € / \mathrm{m}$ the cost can be calculated according to Equation 6.

$$
C_{H_{-} H E}=0.9 \cdot n_{\text {fin }} \cdot L_{c}
$$

The thermosyphons proposed as cold side heat exchangers can not be purchased in the market. To estimate their price a unit cost per thermal power to be dissipated to the ambient has been established according to the cost of a SEREVA condenser, with similar characteristics and employed in commercial refrigeration systems [32]. To include the value of the evaporators manufacture this price ${ }_{450}$ has been multiplied by 1.5 resulting in a cost of $0.09 € / \mathrm{W}$. As the computational model determines the heat released by the cold side heat exchangers $\dot{Q}_{T S P_{i}}$, the cost of this part can be easily estimated with Equation 7 .

$$
C_{C_{-} H E}=0.09 \cdot \sum_{i}^{N_{T S P}} \dot{Q}_{T S P_{i}}
$$

By including the finned heat exchanger on the interior walls of the duct, the pressure losses of the gas flow raise, increasing the electric consumption of the fan that propels the current. It would also be necessary to replace the original fan with a more powerful one, that could overcome the greater losses. This fact will add a charge to the installation cost that has been considered setting a unit cost of the extra electric power of $0.4 € / \mathrm{W}[33]$. Hence, the fan ${ }^{465}$ cost would be estimated according to Equation 8 .

$$
C_{\text {fan }}=0.4 \cdot \dot{W}_{a u x}
$$

${ }_{435}$ The last charge considered in these estimations is the cost 470 of every extra element included in every thermoelectric generator, $C_{\text {extra }}$, such as insulation material, assembly elements (screws, nuts, etc) and thermal interface materials. In this regard, the price of the insulation material has 440 been considered $5 € / \mathrm{m}^{2}$; for every assembly element $0.1 €$; and $10 € / \mathrm{m}^{2}$ for the interface material.

Knowing the charges of every element involved in the 475 thermoelectric generator and, thus, the total cost of the system, $C_{\text {total }}$, once the electric power output is estimated, the installation cost can be determined. This parameter represents the price that it is necessary to pay for every unit of electric power that the designed system is able to produce; and it is formulated in $€ / \mathrm{W}$.

Finally, the Levelised Cost of Electricity, LCOE, is analysed. This parameter represents the electricity price that would match the profits obtained from its trading and the installation and operation costs of the generator during its lifetime, see Equation 9.

$$
\left(\begin{array}{c}
\text { lifetime electrical } \\
\text { energy produced }
\end{array}\right) L C O E=\left(\begin{array}{c}
\text { lifetime } \\
\text { costs }
\end{array}\right)
$$

This index is widely used in the energy field and allows the comparison of different power generation technologies. [34]. In other words, the $L C O E$ depicts the necessary price that the electricity obtained from a power plant should have to achieve a break-even point, and can be estimated according to Equation 10. The numerator comprises the sum of the costs over lifetime of the generator and includes the installation cost, the maintenance, fuel costs and dismantling of the facility. The denominator represents de sum of the electrical energy generated over the lifetime.

$$
L C O E=\frac{\sum_{t=1}^{n} \frac{I_{t}+M_{t}+F_{t}+D_{t}}{(1+k)^{t}}}{\sum_{t=1}^{n} \frac{E_{y e a r-t}}{(1+k)^{t}}}
$$

$E_{\text {year_t }}$ represents the electric energy produced every tperiod; $I_{t}$ is the total installation cost; $M_{t}$ the cost related to operation and maintenance; $F_{t}$ the price of the fuel; and $D_{t}$ the plant dismantling costs. The value of every item is updated to current values applying a discount rate, $k$, of $8 \%$ that has been assumed constant [35].

In this case of using thermoelectric generators only an initial investment the first year, $t=1$, has been considered. The operation and maintenance costs have been assumed to be zero, due to the high robustness of these systems. The fuel cost is also zero since the hot gas flow is considered as a free source and the dismantling charges are considered negligible as are in other renewable energy systems, since these costs are made up for the residual value of the power plants [35]. The expected lifetime of the generators has been considered $n=30$ years.

It is worth mentioning that the proposed design is hardly suitable for an existing industrial facility where there are some elements that could difficult the installation of such generators (for instance: insulated pipes, non accessible places or round geometries) and would increase the cost of it to a great extend. However, when designing a duct for a real plant from scratch it would be interesting to consider this proposal as a valid waste heat recovery option.

\section{Results}

This section includes the analysis of the 45 simulations run where 3 factors have been considered: 5 levels for the 


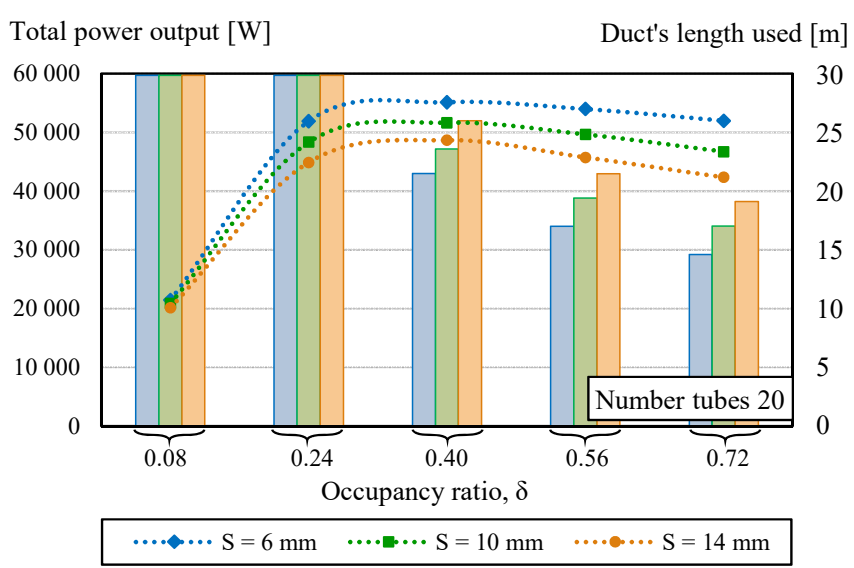

Figure 9: Total power output and length of the duct occupied by the thermoelectric generators for different occupancy ratios and fin spacing, considering 20 tubes in the condenser.

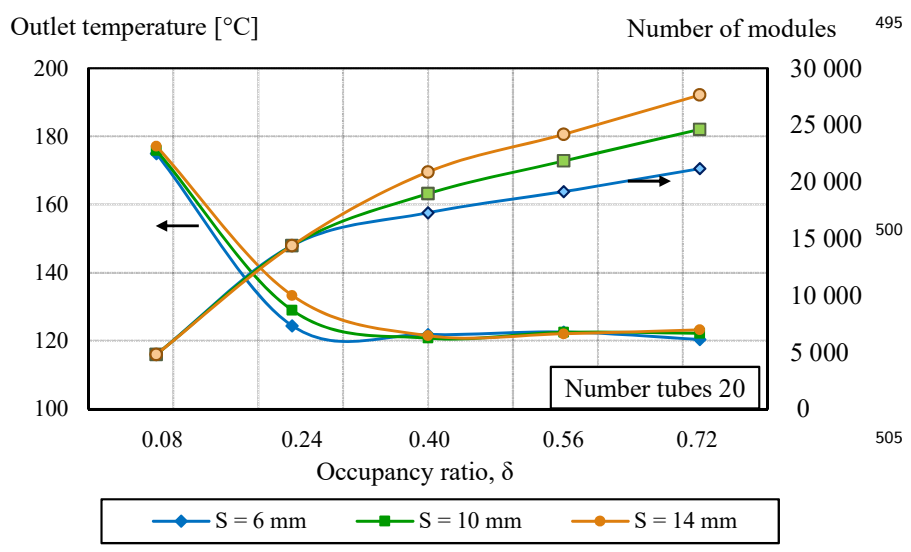

Figure 10: Outlet temperature of the gases and number of thermoelectric modules installed for different occupancy ratios and fin ${ }^{510}$ spacing, considering 20 tubes in the condenser.

occupancy ratio, $\delta ; 3$ levels for the fin spacing, $S$; and 3 different configurations for the cold side thermosyphons, ${ }_{515}$ varying the number of tubes in the condenser, as shown in

${ }_{480}$ Table 2. Section 4.1 considers the electric power generation while Section 4.2 analyses the economic study.

\subsection{Power output analysis}

Figure 9 shows the total electric power obtained from the different proposed thermoelectric generators as well as the length of the duct occupied by them. The power output is represented by the dashed lines as a function of the occupancy ratio and the 3 fin spacings considered in the ${ }_{525}$ hot side heat exchanger: $6 \mathrm{~mm}$ in blue; $10 \mathrm{~mm}$ in green; and $14 \mathrm{~mm}$ in orange. The length of the duct occupied is plotted using the bar chart (with $30 \mathrm{~m}$ maximum), being the limit, as it has been explained before, an outlet temperature of the exhaust gases of $120^{\circ} \mathrm{C}$. Figure 10 represents 530 this outlet temperature of the gases and the number of thermoelectric modules installed for each case.
Table 3: Results of the simulations of waste-heat recovery from a real industrial process.

\begin{tabular}{cc|rrrrrr}
\hline \multicolumn{2}{c}{ Case } & \multicolumn{6}{c}{ Results } \\
$\mathrm{S}$ & $\delta$ & $L_{c}$ & $T_{H^{\circ}}^{\text {out }}$ & $\dot{W}_{\text {gen }}$ & $\dot{W}_{\text {aux }}$ & $\dot{W}_{\text {net }}$ & $E_{\text {year }}$ \\
$\mathrm{mm}$ & - & $\mathrm{m}$ & ${ }^{\mathrm{C}}$ & $\mathrm{W}$ & $\mathrm{W}$ & $\mathrm{W}$ & $\mathrm{MWh}$ \\
\hline \multirow{6}{*}{6} & 0.08 & 30.0 & 175.0 & 21432 & 18640 & 2792 & 22 \\
& 0.24 & 30.0 & 124.4 & 51893 & 17453 & 34440 & 273 \\
& 0.40 & 21.6 & 121.9 & 55128 & 12495 & 42633 & 338 \\
& 0.56 & 17.1 & 122.6 & 53974 & 9893 & 44081 & 349 \\
& 0.72 & 14.7 & 120.4 & 51986 & 8504 & 43482 & 344 \\
\hline \multirow{6}{*}{10} & 0.08 & 30.0 & 176.0 & 20848 & 7904 & 12944 & 103 \\
& 0.24 & 30.0 & 129.0 & 48316 & 7440 & 40877 & 324 \\
& 0.40 & 23.7 & 120.8 & 51648 & 5810 & 45838 & 363 \\
& 0.56 & 19.5 & 122.5 & 49657 & 4775 & 44882 & 355 \\
& 0.72 & 17.1 & 122.2 & 46731 & 4188 & 42543 & 337 \\
\hline \multirow{4}{*}{14} & 0.08 & 30.0 & 177.2 & 20132 & 6369 & 13763 & 109 \\
& 0.24 & 30.0 & 133.3 & 44894 & 6022 & 38872 & 308 \\
& 0.40 & 26.1 & 121.6 & 48667 & 5143 & 43524 & 345 \\
& 0.56 & 21.6 & 122.1 & 45741 & 4259 & 41482 & 329 \\
& 0.72 & 19.2 & 123.3 & 42345 & 3787 & 38558 & 305 \\
\hline
\end{tabular}

As it can be seen in Figure 9 and Figure 10 when considering low occupancy ratios, which means the installation of fewer thermoelectric modules, a slight cooling of the hot gases is achieved covering the whole length of the duct without getting to the temperature limit of $120^{\circ} \mathrm{C}$. So, for example, with an occupancy ratio of $\delta=0.08$, the outlet temperature of the gases is around $175^{\circ} \mathrm{C}$ in all cases. With $\delta=0.28$ the outlet temperature drops to $130{ }^{\circ} \mathrm{C}$, also allowing the occupancy of the whole duct. What it can be seen is that, in this case, the power generation increases, since more energy is taken from the hot gas flow. When the occupancy ratio is increased, the length that can be covered by the generators is reduced since the limite of $120^{\circ} \mathrm{C}$ is reached before getting to the duct height of $30 \mathrm{~m}$.

Other fact seen in the figures is that, the higher the occupancy ratio, the higher the values of the thermal resistances for the hot side heat exchangers. This is reflected in a drop of the electric production caused by a reduction of the temperature difference between faces of the thermoelectric modules. Therefore, the maximum power generation is achieved when considering middle occupancy ratios, which allows appropriate values for the thermal resistance of the hot side heat exchangers and enables maximum use of the heat available in the hot gases, that is, chilling the gas flow to $120^{\circ} \mathrm{C}$.

All the results shown above, and extended in Table 3, correspond to thermoelectric generators whose thermosyphons have 20 tubes in their condensers. Figure 11 represents the total power output from the generators as a function of the number of tubes in the condenser considering an occupancy factor of 0.40 . As it can be seen, there is a slight increase in the electric generation, thanks to a reduction of the thermal resistance of the cold side heat exchanger by increasing the number of tubes. However, this growth represents only a $0.5 \%$ in the best case, which is not justified by the increase of the number of tubes, with the corresponding rise in the installation cost. For this reason, the number of tubes in the thermosyphons have been dismissed as a factor of the analysis. From now on, 20 
Total power output [W]

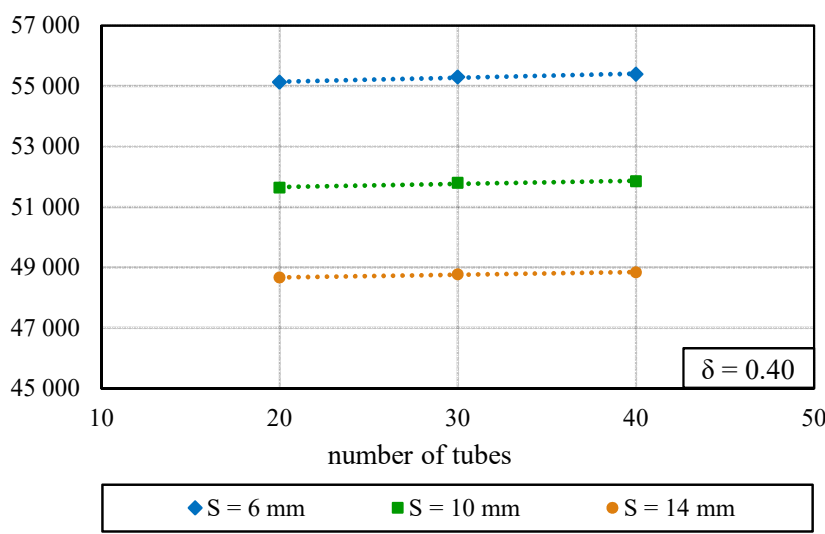

Figure 11: Power output variation with the numbers of tubes in the condensers considering an occupancy ratio of 0.40

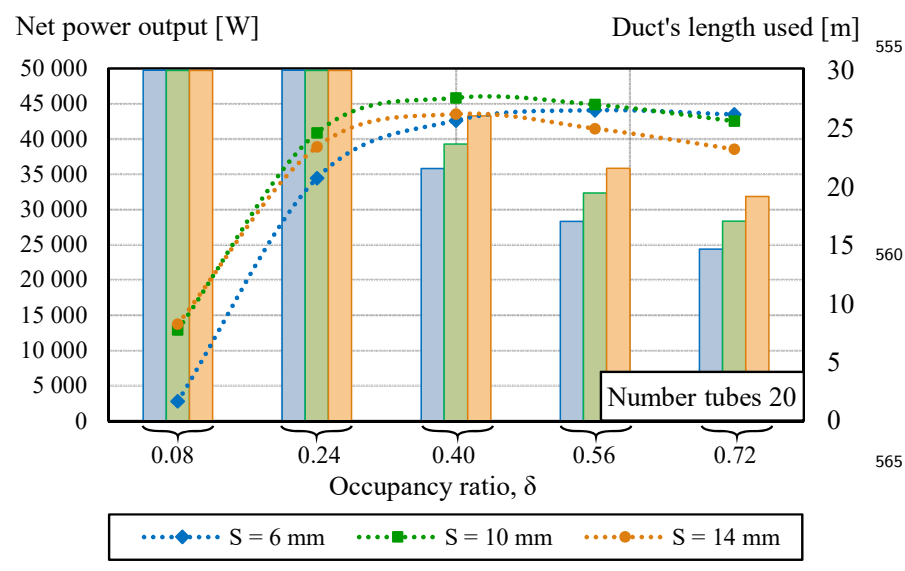

Figure 12: Net power output of the thermoelectric generators as a function of the occupancy ratio and the fin spacing.

tubes will be considered in the condensers.

It is essential to consider the auxiliary consumption of the fan that pumps the hot gas flow through the chimney, which is going to vary according to the pressure losses caused by the fins of the hot side heat exchanger. This ${ }^{575}$ extra electric consumption must be subtracted from the total power output of the thermoelectric generators to obtain the net electric power of the system. As depicted in Figure 4, the hot side heat exchanger with a fin spacing of $6 \mathrm{~mm}$ presents higher pressure losses than the dissipaters ${ }^{58}$ with 10 and $14 \mathrm{~mm}$ fin spacings, therefore, its auxiliary consumption will be higher. Furthermore, this consumption also depends on the length used for the generators, which increases for low occupancy ratios. This extra consumption is shown in Table 3 and the final net power out- ${ }^{58}$ put is represented in Figure 12. The maximum total generation, which was achieved considering the smallest fin spacing, is penalized by the huge auxiliary consumption of the fan. This effect is emphasized when low occupancy ratios are considered, since the whole length of the duct ${ }^{500}$ is used and the extra consumption is higher. With a fin
Installation cost $[€ / \mathrm{W}]$

Duct's length used [m]

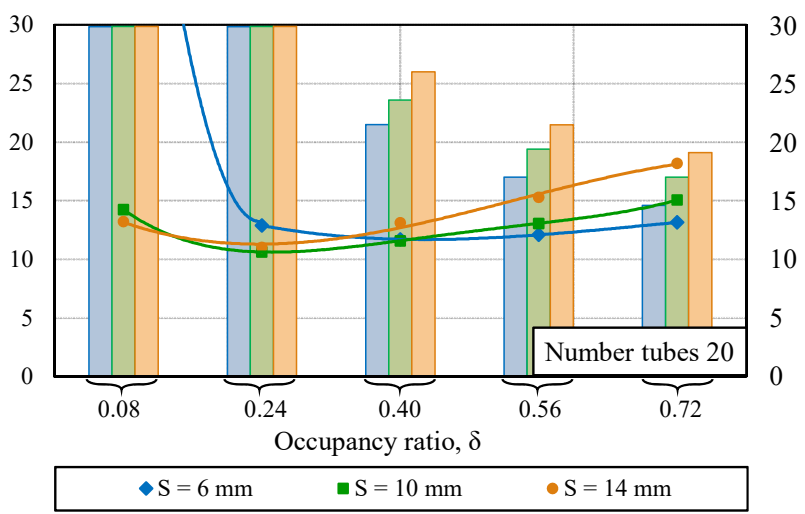

Figure 13: Installation cost of the different thermoelectric generators simulated.

spacing of $10 \mathrm{~mm}$ the net power output is maximized for middle levels of the occupancy ratio, because the extra consumption is not excessive compared to the one with lower $\delta$.

With this spacing, considering an occupancy ratio of $\delta=0.40$ the total power generation amounts to $51648 \mathrm{~W}$. Bearing in mind the auxiliary consumption of the fan, the net electric production drops to $45838 \mathrm{~W}$. Assuming that the manufacturing plant operates for 7920 hours every year, the electric energy that these thermoelectric generators could produce would be $363 \mathrm{MWh}$.

\subsection{Economic analysis}

After the former analysis, now the study from the economic point of view is described. Knowing the characteristics of every generator, the length of the duct used and case, the installation cost has been estimated.

Figure 13 represents the installation costs as a function of the occupancy ratio and the fin spacing considered in the hot side heat exchanger. In this case, the power cost, in $€ / \mathrm{W}$, is proportional to the cost of the electric energy produced, in $€ / \mathrm{kWh}$, since the number of generation hours is constant.

According to these results, the generators with a fin spacing of $14 \mathrm{~mm}$ can be dismissed, since the installation cost is higher than the others simulated. Only with an occupancy ratio of 0.08 the cost is lower, however, as the power output in this case is low it has been also discarded.

Considering higher occupancy ratios, the installation cost is minimized using $6 \mathrm{~mm}$ fin spacing. But, the net electric generation is not maximized with these values.

The minimum installation costs are achieved using middle occupancy ratios, between 0.24 and 0.40 . For this configurations, the fin spacing that optimizes both the net power output and the costs is $10 \mathrm{~mm}$. Specifically, considering an occupancy ratio of 0.24 , the installation cost is minimized to $10.6 € / \mathrm{W}$; whereas using an occupancy ratio of 0.40 a maximum net electric generation of $45838 \mathrm{~W}$ 
Net power output [W]

Installation cost $[€ / \mathrm{W}]$

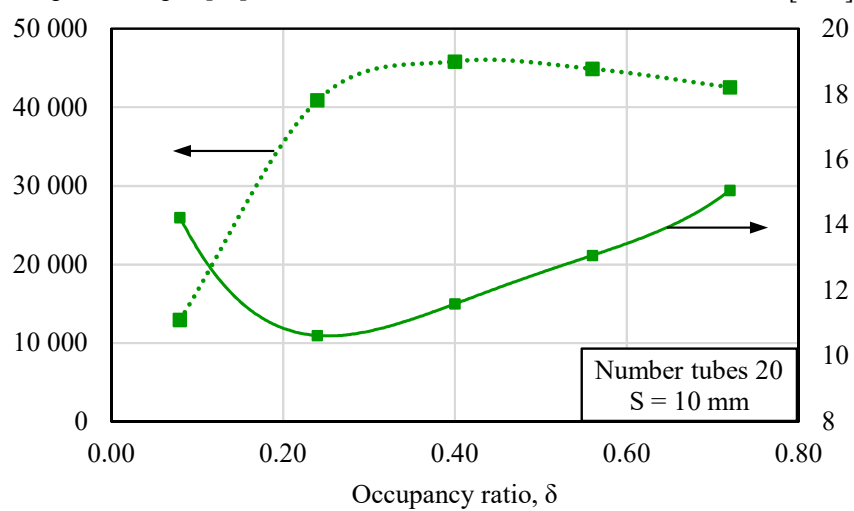

Figure 14: Net power output and installation cost of the optimized thermoelectric generators: $10 \mathrm{~mm}$ fin spacing and 20 tubes in the condenser.

Table 4: Results for two optimized thermoelectric generators: one maximizing the power output, the other minimizing the installation cost. Both have 20 tubes in the condensers of the thermosyphons and $10 \mathrm{~mm}$ fin spacing.

\begin{tabular}{ccccccc}
\hline$\delta$ & $\begin{array}{c}\dot{W}_{\text {net }} \\
\mathrm{W}\end{array}$ & $\begin{array}{c}\eta \\
\%\end{array}$ & $\begin{array}{c}E_{\text {year }} \\
\mathrm{MWh}\end{array}$ & $\begin{array}{c}\text { Investment } \\
€\end{array}$ & $\begin{array}{c}\text { Inst. cost } \\
€ / \mathrm{W}\end{array}$ & $\begin{array}{c}\text { LCOE } \\
\mathrm{c} € / \mathrm{kWh}\end{array}$ \\
\hline 0.24 & 48316 & 3.3 & 324 & 434477 & 10.63 & 14.6 \\
0.40 & 51648 & 3.3 & 363 & 531523 & 11.60 & 15.9 \\
\hline
\end{tabular}

is achieved. Figure 14 represents this combined solution from the power output and the economic point of view using thermoelectric generators with $10 \mathrm{~mm}$ fin spacing on the hot side heat exchanger and 20 tubes in the condenser of the thermosyphons of the cold side.

Table 4 gathers a summary of both solutions. In these final results, considering occuapncy ratios of 0.24 and 0.40 the $L C O E$ of this technology has been estimated (assuming a service life of 30 years), getting a price of 14.6 and $15.9 \mathrm{c} € / \mathrm{kWh}$ respectively.

A comparison between these $L C O E$ results with the prices of other technologies [36] have been made. Figure 15 represents the values for all these power generation systems and, as it can be seen, the optimized thermoelectric generators proposed in this work is within the range ${ }_{640}$ of prices of other renewable energy plants such as offshore wind turbines or concentrated solar power plants.

\section{Conclusions}

This work addresses the prospects of installation of thermoelectric generators in a real process of a manufacturing plant for waste-heat recovery. The productive process has been analysed and several hot spots have been picked up. After comparing temperature and mass flow650 conditions, the curing oven exhaust pipe has been selected for this study.

A design af a thermoelectric generator has been proposed. This system includes a fin dissipater as the hot side

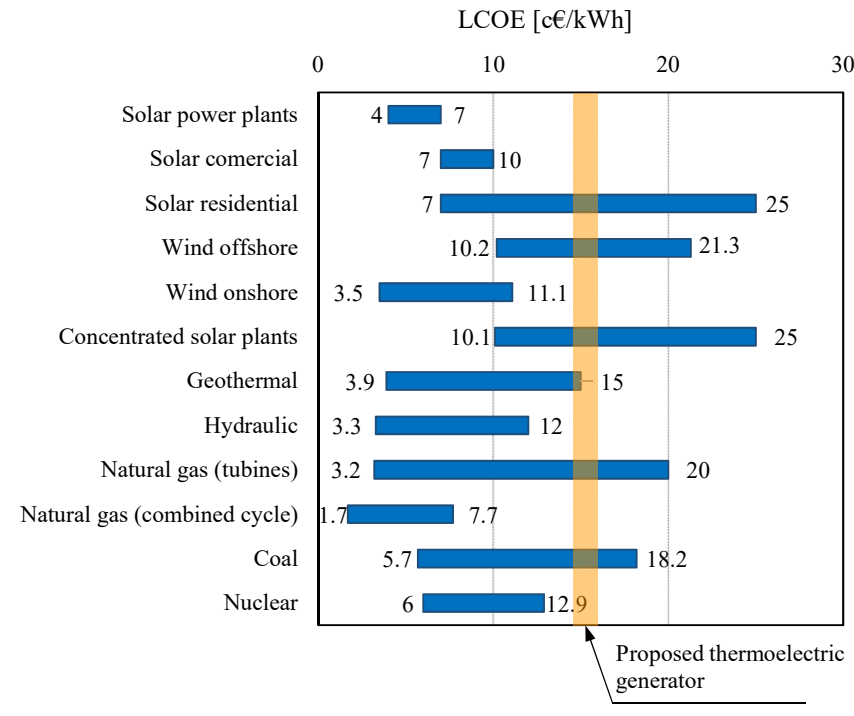

Figure 15: $L C O E$ comparison between different energy sources and the proposed thermoelectric generator. Data obtained from [36].

heat exchanger and a biphasic thermosyphons as the cold side heat exchangers. Commercial thermoelectric modules have been chosen for the simulations.

A combination of two computational models, previously developed and validated, has been made to perform 45 simulations and optimize the design of the thermoelectric generator from power output and economical point of view. These models consider the temperature drop of the hot gases as they flow through the thermoelectric generator, the auxiliary consumption of some elements involved, as the fan that pumps the gases through the pipe and, the configuration of the heat exchangers employed. An economic optimization has been also performed, taken into account the cost of the thermoelectric modules, the heat exchangers, auxiliary elements and assembly components.

The results show a strong influence of the occupancy ratio over the power output of the thermoelectric generators. Low occupancy ratios, $\delta=0.08$, lead to small electric productions, less than $21000 \mathrm{~W}$, since the generators can not absorb enough heat from the gases. With higher values, $\delta$ from 0.24 to 0.72 , the electric production increases up to $45000 \mathrm{~kW}$, reaching the outlet temperature limit of $120^{\circ} \mathrm{C}$. The number of tubes on the condensers of the thermosyphons has turned out to have a small effect over the electric generation. A small fin spacing in the hot side heat exchanger, $6 \mathrm{~mm}$, reduces the thermal resistance of it, but it causes higher pressure losses, which result in a greater electric consumption of the fan that blows the gases, thus, this strongly reduces the electric net power generation. A maximum net power output of $45838 \mathrm{~W}$ is obtained when an occupancy ratio of $\delta=0.40$ and a fin spacing of $S=10 \mathrm{~mm}$ is considered.

The economical and power optimization points do not coincide but both solutions are achieved at medium occupancy ratios and $10 \mathrm{~mm}$ fin spacing. With a $\delta=0.24$ the 
655 installation cost is minimized at $10.6 € / \mathrm{W}$. In both cases, the $L C O E$ is estimated getting prices within the ranges of current energy sources, around $15 \mathrm{c} € / \mathrm{kWh}$. Therefore, the capabilities of waste-heat recovery from industrial pro- ${ }_{720}$ cesses at reasonable prices with thermoelectric generators have been proven.

\section{Acknowledgement}

The authors are indebted to the Government of Navarre funds for economic support of this work, included in the 0011-1365-2018-000101 Research Project; and the Span-730 ish Ministry of Economy and Competitiveness for the economic support thanks to the DPI2014-53158-R project.

\section{References}

[1] Lawrence Livermore National Laboratory, Data Based on DOE/IEA MER (2018), Tech. rep., U.S. Department of Energy (2018).

[2] E. Woolley, Y. Luo, A. Simeone, Industrial waste heat recovery: A systematic approach, Sustainable Energy Technologies and Assessments 29 (2018) 50-59. doi:10.1016/j.seta.2018.07. 001.

[3] H. Jouhara, N. Khordehgah, S. Almahmoud, B. Delpech, 745 A. Chauhan, S. A. Tassou, Waste heat recovery technologies and applications, Thermal Science and Engineering Progress 6 (2018) 268-289. doi:10.1016/j.tsep.2018.04.017.

[4] S. M. Pourkiaei, M. H. Ahmadi, M. Sadeghzadeh, S. Moosavi, F. Pourfayaz, L. Chen, M. A. Pour Yazdi, R. Kumar, Thermo-750 electric cooler and thermoelectric generator devices: a review of present and potential applications, modeling and materials, Energy 186 (2019) 115849. doi:10.1016/j.energy.2019.07.179.

[5] M. A. Alghoul, S. A. Shahahmadi, B. Yeganeh, N. Asim, A. M. Elbreki, K. Sopian, S. K. Tiong, N. Amin, A review of thermo-755 electric power generation systems: Roles of existing test rigs/ prototypes and their associated cooling units on output performance, Energy Conversion and Management 174 (2018) 138156. doi:10.1016/j.enconman.2018.08.019.

[6] M. Nesarajah, G. Frey, Optimized Design of Thermoelectric ${ }_{760}$ Energy Harvesting Systems for Waste Heat Recovery from Exhaust Pipes, Applied Sciences 7 (6) (2017) 634. doi:10.3390/ app7060634

[7] M. F. Remeli, A. Date, B. Orr, L. C. Ding, B. Singh, N. D. N. Affandi, A. Akbarzadeh, Experimental investigation of com-765 bined heat recovery and power generation using a heat pipe assisted thermoelectric generator system, Energy Conversion and Management 111 (2016) 147-157. doi:10.1016/j.enconman. 2015.12.032.

[8] U. Chiarotti, V. Moroli, F. Menchetti, R. Piancaldini, 770 L. Bianco, A. Viotto, G. Baracchini, D. Gaspardo, F. Nazzi, M. Curti, M. Gabriele, Development of a Small Thermoelectric Generators Prototype for Energy Harvesting from Low Temperature Waste Heat at Industrial Plant, Journal of Nanoscience and Nanotechnology 17 (3) (2017) 1586-1591. doi:10.1166/775 jnn.2017.13723.

[9] P. Aranguren, D. Astrain, A. Rodríguez, A. Martínez, Experimental investigation of the applicability of a thermoelectric generator to recover waste heat from a combustion chamber, Applied Energy 152 (2015) 121-130. doi:10.1016/j.apenergy 780 2015.04.077

[10] A. Montecucco, J. Siviter, A. Knox, Combined heat and power system for stoves with thermoelectric generators, Applied Energy 185 (2017) 1336-1342. doi:10.1016/j.apenergy.2015.10.
[11] H. Khalil, H. Hassan, 3D study of the impact of aspect ratio and tilt angle on the thermoelectric generator power for waste heat recovery from a chimney, Journal of Power Sources 418 (2019) 98-111. doi:10.1016/j.jpowsour.2019.02.020.

[12] S. Khanmohammadi, M. Saadat-Targhi, Thermodynamic and economic assessment of an integrated thermoelectric generator and the liquefied natural gas production process, Energy Conversion and Management 185 (2019) 603-610. doi:10.1016/j. enconman.2019.02.034.

[13] A. Habibollahzade, E. Gholamian, P. Ahmadi, A. Behzadi, Multi-criteria optimization of an integrated energy system with thermoelectric generator, parabolic trough solar collector and electrolysis for hydrogen production, International Journal of Hydrogen Energy 43 (31) (2018) 14140-14157. doi:10.1016/j. ijhydene.2018.05.143.

[14] F. Meng, L. Chen, Y. Feng, B. Xiong, Thermoelectric generator for industrial gas phase waste heat recovery, Energy 135 (2017) 83-90. doi:10.1016/j.energy.2017.06.086.

[15] R. Elankovan, S. Suresh, K. Karthick, M. M. M. Hussain, V. P. Chandramohan, Evaluation of thermoelectric power generated through waste heat recovery from long ducts and different thermal system configurations, Energy 185 (2019) 477-491. doi: 10.1016/j.energy.2019.07.039.

[16] M. C. Barma, M. Riaz, R. Saidur, B. D. Long, Estimation of thermoelectric power generation by recovering waste heat from Biomass fired thermal oil heater, Energy Conversion and Management 98 (2015) 303-313. doi:10.1016/j.enconman.2015. 03.103.

[17] O. H. Ando Junior, A. L. Maran, N. C. Henao, A review of the development and applications of thermoelectric microgenerators for energy harvesting, Renewable and Sustainable Energy Reviews 91 (2018) 376-393. doi:10.1016/j.rser.2018.03.052.

[18] P. Aranguren, M. Araiz, D. Astrain, A. Martínez, Thermoelectric generators for waste heat harvesting: A computational and experimental approach, Energy Conversion and Management 148 (2017) 680-691. doi:10.1016/j.enconman.2017.06.040.

[19] M. Q. Khan, S. Malarmannan, G. Manikandaraja, Power generation from waste heat of vehicle exhaust using thermo electric generator: A review, IOP Conference Series: Materials Science and Engineering 402 (1) (2018). doi:10.1088/1757-899X/402/ $1 / 012174$.

[20] K. Anderson, N. Brandon, Techno-economic analysis of thermoelectrics for waste heat recovery, Energy Sources, Part B: Economics, Planning and Policy 14 (4) (2019) 147-157. doi: 10.1080/15567249.2019.1632976.

[21] M. Ebrahimi, E. Derakhshan, Thermo-environ-economic evaluation of a trigeneration system based on thermoelectric generator, two-bed adsorption chiller, and polymer exchange membrane fuel cell, Energy Conversion and Management 180 (2019) 269-280. doi:10.1016/j.enconman.2018.10.093.

[22] E. Massaguer, A. Massaguer, T. Pujol, M. Comamala, L. Montoro, J. R. Gonzalez, Fuel economy analysis under a WLTP cycle on a mid-size vehicle equipped with a thermoelectric energy recovery system, Energy 179 (2019) 306-314. doi: 10.1016/j.energy.2019.05.004.

[23] N. S. Benday, D. M. Dryden, K. Kornbluth, P. Stroeve, A temperature-variant method for performance modeling and economic analysis of thermoelectric generators: Linking material properties to real-world conditions, Applied Energy 190 (2017) 764-771. doi:10.1016/j.apenergy.2016.12.157.

[24] M. Mirhosseini, A. Rezania, L. Rosendahl, Power optimization and economic evaluation of thermoelectric waste heat recovery system around a rotary cement kiln, Journal of Cleaner Production 232 (2019) 1321-1334. doi:10.1016/j.jclepro.2019. 06.011.

[25] E. Cirés, J. Marcos, I. de la Parra, M. García, L. Marroyo, The potential of forecasting in reducing the LCOE in PV plants under ramp-rate restrictions, Energy 188 (2019) 116053. doi: 10.1016/j.energy.2019.116053.

[26] K. Mohammadi, J. G. McGowan, M. Saghafifar, Thermoeconomic analysis of multi-stage recuperative Brayton power cy- 
cles: Part I- hybridization with a solar power tower system, Energy Conversion and Management 185 (February) (2019) 898919. doi:10.1016/j.enconman.2019.02.012.

URL https://doi.org/10.1016/j.enconman.2019.02.012

[27] M. Araiz, A. Martínez, D. Astrain, P. Aranguren, Experimental and computational study on thermoelectric generators using thermosyphons with phase change as heat exchangers, Energy Conversion and Management 137 (2017) 155-164. doi: $10.1016 / j$. enconman .2017 .01 .046 .

[28] Marlow Industries Inc., Marlow TG12-8 Datasheet (2016). URL http://www.marlow.com

[29] S. Lips, J. P. Meyer, Experimental study of convective condensation in an inclined smooth tube. Part II: Inclination effect on pressure drops and void fractions, International Journal of Heat and Mass Transfer 55 (1-3) (2012) 405-412. doi: $10.1016 / \mathrm{j} . \mathrm{ijheatmasstransfer.2011.09.034.}$

[30] TECTEG - Thermoelectric Gencell Technology, Thermoelectric Power Modules (2018).

URL https://tecteg.com/

[31] TEGmart, TEG Modules (2018).

URL https://www.tegmart.com/thermoelectric-modules/

[32] SEREVA Cool on demand, Condensador simple (2018). URL http://sereva.es

810 [33] SODECA, Ventiladores y extractores industriales. CJTCR/R (2018).

URL http://www.sodeca.com/es/

[34] REN21, Renewables 2018 - Global Status Report, Tech. rep., REN21 Secretariat, Paris (2018).

[35] International Energy Agency, Nuclear Energy Agency, Projected Costs of Generating Electricity, Tech. rep., International Energy Agency, Paris (2015).

[36] V. Shah, J. Booream-Phelps, Solar grid parity in a low oil price era, Tech. rep., Deutsche Bank, Frankfurt (2015). 